\title{
Japan stubs its toes on fifth-generation computer
}

\section{- One-year extension to save face - US collaboration called a sham}

\section{Tokyo \& Washington}

JAPAN's once mighty fifth-generation computer project, which in the early 1980 s sent Western governments scurrying to set up competing computer initiatives, has fallen far short of its mark.

The 10-year project was due to finish at the end of this month, but it has lagged so embarrassingly behind schedule that the Japanese government has given the project an extra year to inch closer to its target.

Launched in 1982 by the Ministry of International Trade and Industry (MITI), the fifth-generation project set out to develop a massive 'user friendly' parallel computer with 1,000 processors. Its software was based on logic rather than on classic structured programming. The Japanese initiative raised fears that Japan was about to take over the world's advanced computer market and sparked many competing projects in the West, such as the UK's Alvey project.

But, after ten years and an investment of more than $\$ 400$ million, all Japan has produced is a handful of parallel computers, the largest three of which have only a quarter of the target number of processors. And only a limited number of computer experts know how to operate them.

Despite its failings, the project is receiving an extra $£ 3,600$ million (nearly US $\$ 30$ million) from MITI in fiscal year 1992, and project researchers are rushing to assemble a 512-processor machine in time for a final international conference on the project in June.

The fifth-generation computer project is a classic example of how the rigid Japanese bureaucracy can foil a national project. By the mid-1980s, it was clear that other approaches to parallel computing not based on traditional artificial intelligence techniques, such as neural networks or the massively parallel machines created by Thinking Machines Inc. of the United States, looked more promising. But having told the Ministry of Finance that it would build a 1,000-processor machine, MITI had no choice but to continue towards that goal. MITI officials fully realize their failings, however, and in their next 'sixth generation' computer project they intend to set more flexible goals (see next page).

One ray of hope for the fifth-generation computer came in 1990. Some of the researchers at the project's Institute of New Generation Computer Technology (ICOT) in Tokyo established a high-ca- pacity computer link with the US Argonne National Laboratory to try and use one of the prototype fifth-generation computers in ICOT to solve biological problems associated with the human genome project (Nature 345, 466; 1990).

But that collaboration went disastrously awry (see sidebar), and similar collabora-

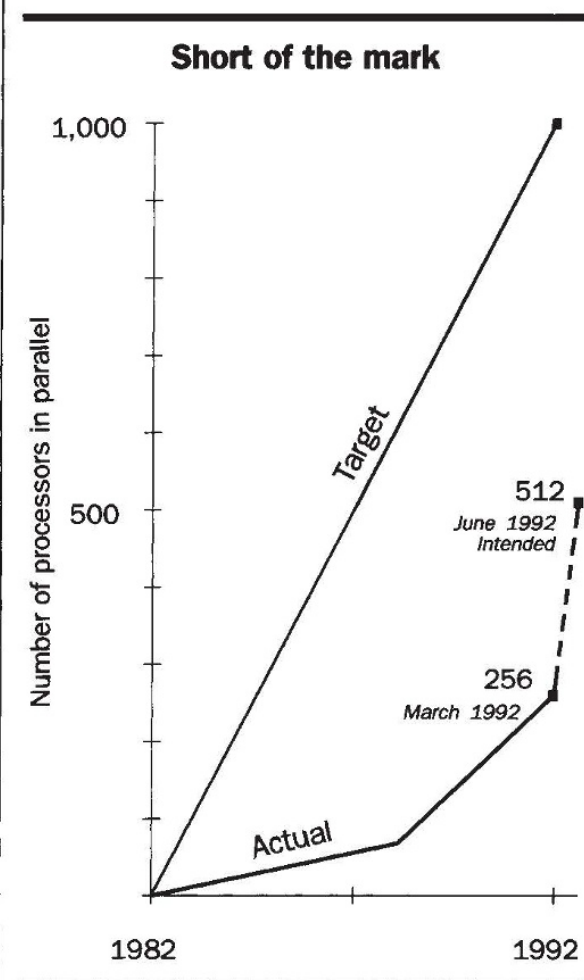

tions with the US National Institutes of Health (NIH) and the Lawrence Berkeley National Laboratory (LBL) are essentially moribund. US researchers found the fifthgeneration computers to be slow, cryptic and filled with bugs. And the documentation that came with them was written with Kanji characters, which were never translated into English.

As a result, the fifth generation machines in the United States are now "essentially doorstops" that are used mostly for electronic mail, says one researcher. At NIH, "we're not using their hardware or their software," says George Michaels, a NIH geneticist. US researchers say that the Japanese were more interested in showing the world that the machines were being used by NIH and US national laboratories than in any real collaborations. "The reason the machines came here was essentially PR," Michaels says.

(Continued on page 274)

\section{Collaboration vetoed}

IN January 1991, with the United States preparing for war in the Middle East and anti-Japanese sentiment running high, officials at the US Department of Energy (DOE) shut down one of the three US collaborations with the Japanese fifth-generation computer project in fear of a backlash from Congress.

The official reason was that the US team at DOE's Argonne National Laboratory had not obtained proper approval before visiting Japanese laboratories and accepting two computers from them. But, in fact, they acted after reading an article about the collaboration in Supercomputing Review. Being seen as sharing technology with such a fierce rival, DOE officials told scientists, could cause problems for the agency when it came time to defend its budget before Congress.

In October, the principal US collaborator in the project, Ross Overbeek, resigned in protest after a long war of memoranda. Overbeek declined to discuss the case, but others say that he objected to the DOE claim that the collaboration might lead to "inappropriate technology transfer to the Japanese."

In fact, no technology was transferred - but not because the Argonne team had refused to do so. The Japanese themselves had shown little interest in the software the Argonne researchers had developed.

Ironically, the collaboration had effec. tively ended before the controversy began. Similar collaborations at the National Institutes of Health (NIH) and the Lawrence Berkeley National Laboratory were not affected by the DOE decision, mostly because the officials who ran those programmes were less concerned about the politics of Japanese collaboration.

First announced in June 1990, the Argonne collaboration was intended to develop software collaboratively that could use the logic-based techniques of the fifth generation computer project to analyse genome data (see Nature 345, 467; 1990). But like other US-Japanese collaborations in the project (see adjacent story), it quickly ran into technical problems.

"On the surface, it looked like Washington put pressure on the collaboration to stop," says Rick Stevens, director of Argonne's mathematics and computer science division. "But from our standpoint, it wasn't going anywhere, anyway."

Indeed, DOE officials say, that lack of progress was part of their concern. Collaboration should be "symmetrical", says David Nelson, DOE's director of scientific computing. "Just because someone gives you a free machine," he says, "doesn't make it a collaboration."

Outside observers have another perspective. "It was an amazing overreaction" in a time of political tension, says George Michaels, a NIH genetics researcher. C.A. 